УДК $81 ’ 42$

\title{
ПРАГМАТИЧЕСКАЯ АТТРАКЦИЯ: ПОСТАНОВКА ПРОБЛЕМЫ И ВВЕДЕНИЕ ТЕРМИНА
}

\author{
КРАВЧЕНКО Н. К. \\ доктор филологических наук, профессор \\ Киевский национальный лингвистический университет \\ ПАСТЕРНАК Т. А. \\ NKravchenko@outlook.com \\ кандидат филологических наук, доцент \\ Наииональный университет биоресурсов и природопользования Украины \\ tanya.pasternak@gmail.com
}

\begin{abstract}
В статье обосновывается и вводится в научный обиход новый лингвистический термин “прагматическая аттракция” по аналогии с существующими в лингвистике понятиями паронимической, семантической и синтагматической аттракции на основании взаимообусловленности и взаимном “притяжении” различных прагматических феноменов. Идентифицированы и описаны основные типы прагматической аттракции: аттракция информационно-прагматических параметров (иллокутивные смыслы, импликатуры, пресуппозиции), аттракция интенционально-стратегических параметров (коммуникативные конвенции, роли, стратегии, тактики, речевые ходы), аттракция неоднородных параметров (взаимообусловленность параметров двух первых типов аттракции), а также проанализированы особенности структурных взаимосвязей между выявленными типами.

Ключевые слова: прагматическая аттракция, типы прагматической аттракции, структурные взаимосвязи, иллокуция, импликатура, коммуникативные конвенции.
\end{abstract}

\section{ПРАГМАТИЧНА АТРАКЦІЯ: ФОРМУЛЮВАННЯ ПРОБЛЕМИ ТА ВВЕДЕННЯ ТЕРМІНА}

Стаття присвячена введенню в науковий обіг нового лінгвістичного терміна “прагматична атракиія" за аналогією з поняттями паронімічної, синонімічної й синтагматичної атракції на основі взаємозумовленості й взаємотяжіння різних прагматичних феноменів. Мета статті - довести релевантність вказаного терміна, з'ясувати його семантичні межі та співвідношення з іншими лінгвістичними поняттями.

Методи. Дослідження базується на методах прагматичного аналізу, структурного аналізу та текстового аналізу.

Результати. У роботі визначено та описано три основні види прагматичної атракції. Перший тип - це залучення інформаційних та прагматичних параметрів, пов'язаних 3 нав'язуванням неявних значень та вирішенням ілокутивних значень, імплікатур (як умовних, так і нестандартних) та припущень (прагматичних, семантичних тощо). Другий передбачає залучення інтенсифікаційних та стратегічних параметрів, які визначають способи оптимізації інтерактивності: комунікативні звичаї, комунікативні ролі, стратегії, тактики, та мовленнєвих перетворень. Третій полягає в застосуванні неоднорідних параметрів, що поєднує умови та способи прикріплення прагматичної інформації 3 попередніх двох категорій. У роботі проаналізовано особливості структурних взаємозв'язків між цими типами прагматичної атракції.

Побудовано ієрархію інтенційно-стратегічних параметрів, що визначають розвиток прагматичної атракції, очільне місце в цій ієрархії відведено комунікативним конвенціям як ритуалізованим стратегіям, або принципам комунікації. В універсально-типологічному плані основними є принцип співробітництва, який реалізується за допомогою чотирьох відомих максим (стратегій) кооперацій, і принцип ввічливості, який утілений у стратегіях позитивної, негативної ввічливості, а також стратегії bald-on-record i bald-off-record. 
Кравченко Н. К., Пастернак Т. А. Прагматическая аттракция: постановка проблемы и введение термина

Висновки. Підсумовано, що схарактеризовані типи прагматичної атракції мають специфічні види структурних зв'язків: неієрархічний взаємозв'язок однорідних параметрів (перший тип прагматичного притягання), ієрархічний взаємозв'язок однорідних параметрів (другий тип прагматичного притягання) та ієрархічний взаємозв'язок неоднорідних параметрів (третій тип прагматичного тяжіння).

Ключові слова: прагматична атракція, типи прагматичної атракції, структурні взаємозв'язки, ілокуція, імплікатура, комунікативні конвенції.

\section{PRAGMATIC ATTRACTION: SETTING THE PROBLEM AND INTRODUCTION THE TERM}

KRAVCHENKO Nataliia Kymivna

Doctor of Sciences (Philology), Professor Kyiv National Linguistic University NKravchenko@outlook.com

PASTERNAK Tetiana Anatoliivna

Candidate of Scinces (Philology), Assistant Professor National University of Life and Environmental Sciences of Ukraine tanya.pasternak@gmail.com

Introduction. The paper focuses on the defining a new linguistic term of pragmatic attraction, starting a case-study for its grounding in the system of scientific terms and notions.

Purpose. The paper aims at defining the term "pragmatic attraction" by analogy with already used in linguistics notions, such as paronymic attraction, semantic attraction, and syntagmatic attraction based on its interconditionality and mutual "attraction" of different pragmatic phenomena.

Methods. The research is based on the methods of pragmatic analysis, structural analysis and textual analysis.

Results. The paper identified and described three main types of pragmatic attraction. The first type is the attraction of information and pragmatic parameters connected with attaching implicit meanings and dealing with illocutionary meanings, implicatures (both conventional and non- conventional), and presuppositions (pragmatic, semantic, etc). The second one is the attraction of intensional and strategic parameters, which specifies the ways to optimize interactivity: communicative conventions, communicative roles, strategies, tactics and speech turns. The third one, the attraction of heterogeneous parameters, which combines the conditions and the ways to attach pragmatic information from the previous two categories. The paper analysed the peculiarities of structural interrelations among these types of pragmatic attraction.

Conclusions. We have concluded that the outlined types of pragmatic attraction have specific kinds of structural relations: non- hierarchical interrelation of homogeneous parameters (first type of pragmatic attraction), hierarchical interrelation of homogeneous parameters (second type of pragmatic attraction), and hierarchical interrelation of heterogeneous parameters (third type of pragmatic attraction).

Key words: pragmatic attraction, types of pragmatic attraction, structural interrelations, illocution, implicature, communicative conventions.

Постановка проблемы и обоснование актуальности ее решения. Проблема прагматической аттракции является новой и, соответственно, неисследованной в современной лингвопрагматике. Актуальность темы статьи не вызывает сомнения, так как изучение феномена аттракции на прагматическом уровне может пролить свет на такие неизменно актуальные проблемы современного языкознания, как структурированность речи / коммуникации, иерархия и таксономия прагматических параметров дискурса, принципы обеспечения дискурсивной целостности. Термин прагматическая аттракция вводится по аналогии с известными в лингвистике понятиями: паронимическая аттракция (эксплицитная ассоциативная связь двух слов на основе сходства их фонетической формы и ее графического выражения) (Воронюк, 1998; Дащенко, 
1996), семантическая аттракция (эксплицитная и имплицитная ассоциативная связь двух слов на основе сходства элементов их содержания) (Костина, 2017; Маковский, 1971) и синтагматическая аттракция (эксплицитная ассоциативная связь субстантивов на основе общности зоны их сочетаемости) (Полтавець, 2013).

Помимо этого, значение термина прагматическая аттракция является, на наш взгляд, самоочевидным вследствие прозрачности его внутренней формы: взаимообусловленность и взаимное "притяжение” различных прагматических феноменов.

Цель статьи - введение в научный обиход и обоснование термина прагматическая aтmракция. Задачи - идентифицировать и описать основные типы прагматической аттракции, а также проанализировать особенности структурных взаимосвязей между выявленными типами.

Изложение основного материала исследования. Наиболее очевидный пример прагматической аттракции - неизменная связь стратегий негативной вежливости (вежливости, уважения и социальной дистанции) с непрямыми актами и с нарушением максимы количества информации It might be useful to take overall view. В приведенном примере негативная вежливость выражается посредством непрямого акта с имплицированной иллокуцией директива (совета). Высказывание является структурно усложненным, инкорпорируя маркеры митигации и косвенности: средства имперсонализации, генерализации, модальный глагол. Структурное усложнение, которое иконично воспроизводит сложность (неловкость) ситуации совета (отказа, несогласия и др.), указывает на непреференциальность речевого хода (dispreffered move в терминах конверсационного анализа) и, одновременно, сигнализирует о нарушении максимы количества информации. В свою очередь, отклонение от максимы служит триггером конверсационной импликатуры, которая выводится на основе иллокуции непрямого акта с привлечением контекста. Если продолжить анализ этого примера в аспекте институционального дискурса, то в контексте политической коммуникации негативная вежливость, импликатура, косвенный речевой акт, в свою очередь, коррелируют со стратегией / тактикой ухода от ответственности.

Анализ немногочисленной теоретической литературы, посвященной интерференции прагматических явлений, а также предварительное исследование авторов этой статьи, проведенное на материале различных видов дискурса, позволил выделить три типа прагматической аттракции:

1) Аттракция информационно-прагматических параметров - взаимная обусловленность различных прагматических феноменов, связанных с приращением имплицитных смыслов. К этой категории относятся иллокутивные смыслы, импликатуры (конвенциональные и конверсационные), пресуппозиции (прагматические, семантические) и др.

2) Аттракция интенционально-стратегических параметров - взаимная обусловленность способов оптимизации интерактивности: коммуникативных конвенций, ролей, стратегий, тактик и речевых ходов.

3) Аттракция неоднородных параметров: обусловленность первой категории параметров, то есть средств приращения прагматической информации второй категорией.

Обозначенные типы выявляют различные виды структурных отношений: неиерархическую взаимосвязь однородных параметров (первый тип прагматической аттракции), иерархическую взаимосвязь однородных параметров (второй тип прагматической аттракции) и иерархическую взаимосвязь неоднородных параметров (третий тип прагматической аттракции).

Теоретические предпосылки для изучения первого типа прагматической аттракции сформированы, главным образом, зарубежными работами в области прагматической семантики или формальной прагматики. Исследователей интересовало, в первую очередь, сходство тех структурно маркированных прагматических феноменов, которые базируются на общих лингвистических показателях и, соответственно, предполагают определенное сходство в процессах инференции (выведения) смыслов на основе таких индексов. 
Кравченко H. К., Пастернак T. А. Прагматическая аттракция: постановка проблемы и введение термина

В частности, в работах Лауры Картунен, Стенли Питерса и Энн Зенен (Karttunen \& Peters, 1979; Karttunen \& Zaenen, 2005) показаны соответствия между конвенциональными импликатурами и семантическими пресуппозициями в триггерах их актуализации и моделях выведения. Кристофер Потс определяет конвенциональные импликатуры и конвенциональные (то есть семантические - aвторы) пресуппозиции как контекстуально независимые импликации (context-free entailments), отграничивая их от конверсационных импликатур и прагматических пресуппозиций (Potts, 2005). В то же время, К. Потс (2013, с. 28) и Л. Хорн (Horn, 2007) высказывают предположение о том, что пресуппозиции всегда отсылают к уже известной информации, в то время как импликатуры - к новой, составляющей предмет высказывания (at-issue content).

Другая возможность связи между однопорядковыми прагматическими параметрами конвенциональными импликатурами и перформативами - была продемонстрирована еще в работах Г. П. Грайса (Grice, 1989), а также в исследованиях Э. Баха (Bach, 1999; 2012) и С. Рибера (Rieber, 1997).

В отечественной лингвистике проблема взаимосвязи различных прагматических смыслов, имеющих общие формально-структурные показатели, исследовалась в работах Н. К. Кравченко (2017a; 2017b) и Т. А. Пастернак (Kravchenko \& Pasternak, 2018). В частности, Н. К. Кравченко, введя понятие сложной иллокуции прямых речевых актов (2017а), определяет коррелятивные связи между составляющими такой иллокуции (Illocution-Expander, Illocution-Intensifier и Assessment Illocution), конвенциональными импликатурами и семантическими пресуппозициями. В другой работе исследовательницы (Kravchenko, 2017b) доказывается взаимосвязь между иллокуцией непрямых речевых актов, конверсационной импликатурой и прагматической пресуппозицией, что определяется совпадением их триггеров и процедур инференции. В частности, обосновывается вывод о том, что иллокуции непрямых актов нередко базируются на конверсационных импликатурах. Соответственно, нарушение кооперативных максим служит прагматическим триггером актуализации иллокутивной силы. При этом тип отношений между импликатурой и иллокуцией непрямых речевых актов зависит от критерия идиоматичности (idiomaticity) или инференциональности (inferentiality) акта, а также от степени трансформации иллокутивной силы. Идиоматичные акты, а также транспонированные инференциальные акты (то есть те, в которых первичная иллокутивная сила меняет тип самого акта, - например, констатив на директив - aвmopbl) образуют с конверсациональной импликатурой отношения соответствия: говорящий сознательно нарушает одну или более кооперативных максим, чтобы сообщить первичную иллокуцию (т.е., первичный иллокутивный акт - aвторы). Второй тип отношений - отношения зависимости или причинно-следственной связи. Он имеет место в том случае, когда иллокуция не совпадает с импликатурой, а выводится на ее основе. Такой тип взаимодействия характерен для большей части нетранспонированных актов (то есть речевых актов, в которых дополнительная иллокуция присутствует, но не меняет типа самого акта aвmopbl). Наконец, отдельным подтипом взаимосвязей служит отношение "посредничества" (mediation) - когда конверсационная импликатура фокусируются на условиях успешности (Felicity conditions), с учетом которых, в свою очередь, выводится иллокуция непрямого акта.

В аспекте взаимосвязи таких прагматических феноменов, как иллокуции непрямых актов и прагматические пресуппозиции, доказано, что идиоматичность непрямых актов базируется, главным образом, на конвенционально-коммуникативных пресуппозициях. В то же время, конвенциональная “исчислимость” иллокуции непрямых актов “ослабляется” с увеличением значимости контекста, то есть ситуационных пресуппозиций.

Второй тип прагматической аттракции - иерархическая взаимосвязь однородных параметров. Такая связь представляется наиболее “прозрачной” и исследованной при описании стратегического аспекта институциональных дискурсов. В частности, наблюдение о том, что стратегии реализуются в тактиках, а тактики - в коммуникативных ходах является едва ли 
не “общим местом” в лингвистической литературе. При этом на такую иерархическую связь параметров не влияет ни тип стратегии, ни различия в интерпретации этого понятия различными школами дискурс-анализа.

В частности, можно понимать стратегии в универсально-типологическом плане (например, в ракурсе конверсационного анализа (Jefferson, 1972; Sacks, 1992; Schegloff, 2000) - как правила ведения разговора, посредством которых люди “ориентируются” в нем и ориентируют друг друга на некоторый базисный нормативный порядок. В таком случае будут выделяться стратегии взятия и удержания инициативы, коммуникативного доминирования в разговоре, введения в разговор рассказа, поправки, стратегия получения релевантного или преференциального речевого хода, стратегия начала и завершения, стратегия создания позитивной атмосферы (стратегия “ненавязчивости”) для обсуждения топикальной темы. В свою очередь, такие стратегии реализуются в тактиках и речевых кодах: стратегия получения релевантного или преференциального речевого хода - в тактике введения боковой секвенции и соответствующих речевых ходах разъяснения, выражения удивления, убеждения и др.; стратегия создания позитивной атмосферы (“ненавязчивости”) - в тактике пре-секвенций (предваряющих секвенций для сохранения лица одного или обоих участников посредством выявления субъективных обстоятельств другой стороны перед тем, как высказать просьбу / приглашение / требование). Каждый ход, в свою очередь, предопределяет мену коммуникативных ролей, которая, собственно и служит механизмом развития диалога.

Второй тип стратегий - стратегии кооперации (Grice, 1975) и стратегии вежливости (Brown \& Levinson, 1987) коррелируют с конверсационно-аналитическими стратегиями (см. выше). Так, стратегия “ненавязчивости” с тактикой использования пре-секвенций совпадает со стратегией 4 негативной вежливости (Минимизируй степень вмешательства, давления, принуждения), стратегия получения релевантного или преференционального речевого хода, стратегия начала и завершения разговора коррелируют с кооперативными максимами релевантности и стиля. Тактики прерывания собеседника и наложения разговора (overlapping) могут быть как актами, угрожающими лицу (при реализации стратегии коммуникативного доминирования), так и тактиками реализации стратегии позитивной вежливости (если прерывания и наложения вызваны эмпатийным проявлением интереса к собеседнику).

В этой связи, можно предположить, что пересечение категорий таких различных по своим установкам и исследовательским принципам направлений, как конверсационный анализ и теория лица и вежливости, возможно, благодаря феномену взаимообусловленности прагматических феноменов, который обозначен в нашем исследовании зонтичным термином “прагматической аттракции”.

Третий тип стратегий (помимо конверсационных, стратегий кооперации и вежливости) - как техник воздействия на адресата, описан практически для всех известных типов дискурса (Дмитрук, 2006; Иссерс, 2002; Пастернак, 2011). Такие стратегии (прежде всего, институциональные) реализуются в тактиках, составляющими которых являются коммуникативные хода, которые при исследовании институционального и, в особенности, идеологически нагруженного дискурса нередко отождествляются с семантическим ходом или манипуляторным приемом. В частности, семантический ход “приведение примера” (Ранее также сообщалось о том, что...) показывает, что общее мнение не “надумано”, а основано на конкретных фактах (опыте), реализуя, тем самым, тактику усиления фактологичности информации, которая, в свою очередь, подчинена стратегии обобщения частной модели до более общей групповой схемы (стратегии сверхобобщения, по Т. ван Дейку). Приемы сдвига / переноса (transfer) (I have no problem with X, but my clients...); кажущегося сочувствия (apparent empathy) (They have had lots of difficulties in their own country, but...) и др. выявлют тактику возражения под видом согласия (“может быть и Х, но У” означает “уверен, что не X”), которая реализует стратегию позитивной саморепрезентации говорящего в качестве терпимого и широко мыслящего, с социально приемлемыми оценками. 
Кравченко H. К., Пастернак T. А. Прагматическая аттракция: постановка проблемы и введение термина

Иерархию интенционально-стратегических параметров “возглавляют” коммуникативные конвенции - как “ритуализированные” стратегии или принципы коммуникации. В универсальнотипологическом плане основными являются принцип сотрудничества, который реализуется посредством четырех известных максим (стратегий) коопераций, и принцип вежливости, который воплощен в стратегиях позитивной, негативной вежливости, а также стратегии bald-on-record и bald-off-record. Для конверсационно-аналитических исследований такой универсальной конвенцией служит, на наш взгляд, принцип релевантности, которым заданы все перечисленные выше стратегии регламентации разговора и который предопределяет нормативность “естественной речи” как способность предшествующего высказывания генерировать содержание последующего, что получает свое выражение в теории адъяцентных пар и условной релевантности (действия связаны друг с другом через влияние нормы, требующей совершения первого действия, если произошло второе). Согласно теории релевантности Д. Шпербер и Д. Уилсона (Sperber \& Wilson, 1995), принцип релевантности “применяется без исключения", то есть к нему можно свести все четыре максимы кооперации. Это естественная характеристика любого разговора, которая проявляется независимо от соблюдения, нарушения или игнорирования коммуникантами кооперативных принципов (так как говорящий или читатель будет привлекать те когнитивные контексты, в которых высказывание собеседника или автора станет осмысленным).

Помимо универсально-типологического аспекта, конвенции могут дифференцироваться в институциональном и лингвокультурном (этноспецифическом) планах.

Лингвокультурные (этноспецифические) конвенции - это знания и правила коммуникативностратегического поведения, принятые в определенной лингвокультуре и связанные с коммуникативным потенциалом этнокультурных концептов “скромность”, “privacy”, “меншовартість” и т. д.

Логично предположить, что лингвокультурные конвенции корректируют применение как универсально-типологических (вежливости, сотрудничества, релевантности), так и институциональных стратегий, что подтверждается, в частности, исследованиями межкультурной коммуникации в различных сферах - бизнеса, политики и др. (Корольова, 2008; Славова, 2006; Шейгал, 2000).

Третий тип прагматической аттракции выявляется, в частности, в заданности информационно-прагматических параметров интенционально-стратегическими. В этом аспекте с проблемой прагматической аттракции (без использования этого термина) в той или иной мере связаны все современные исследования, посвященные стратегическим или манипулятивным характеристикам институционального дискурса - так как изучение дискурсивного воздействия сводится, прежде всего, к выявлению неявных смыслов (политических, социальных и др.), которые могут быть спрятаны не только от реципиента, но и от автора (Kravchenko \& Pasternak, 2016).

Выводы и перспективы дальнейших исследований. В случае универсальных стратегий наиболее очевидной и, соответственно, изученной представляется “конвенциональная” связь стратегий негативной вежливости с использованием непрямых речевых актов, позволяющих минимизировать навязывание собеседнику своей точки зрения, совета, просьбы и др. В аспекте взаимосвязи вежливости и косвенности убедительные результаты были получены в работах Дж. Лича (Leech, 1983) и П. Браун и С. Левинсона (Brown \& Levinson, 1978), которые показали, что вежливость является главной мотивацией косвенности. Помимо этого, Дж. Лич (26) показывает очевидные корреляции между принципом вежливости с его семью максимами и определенными типами речевых актов. В работах украинских авторов дальнейший спектр взаимосвязей между речевыми актами и вежливостью устанавливается в ракурсе критериев, триггеров и условий успешности иллокутивных актов. В частности, Н. К. Кравченко 
и Т. А. Пастернак (Kravchenko \& Pasternak, 2016) определяют корреляции между стратегиями вежливостии (bald-on-record, bald-off-record, positive and negative politeness strategies) и типами речевых актов, наиболее характерными для их реализации; выявляют зависимости между видами “угрозы” лицу, сохранения и восстановления лица и категориями “прямолинейность / косвенность"; доказывают, что стратегии, восстанавливающие лицо, реализуются посредством непрямых актов, первичный иллокутивный смысл которых восстанавливается по правилам извлечения конверсационной импликатуры.

\section{ЛИТЕРАТУРА}

Воронюк, О. В. (1998). Паронімічна атракиія в заголовку текстів англомовної масової комунікаиії. (Автореф. дис. канд. філол. наук). Одеса.

Дащенко, Н. Л. (1996). Паронімічна атракиія в украӥнській поезії $60-80-x$ років XX cm. (Автореф. дис. канд. філол. наук). Київ.

Дмитрук, О. В. (2006). Маніпулятивні стратегї̈ в сучасній англомовній комунікаиії (на матеріалі друкованих та інтернет-видань 2000-2005 років). (Автореф. дис. канд. філол. наук). Київ.

Иссерс, О. С. (2002). Коммуникативные стратегии и тактики русской речи. Москва: Едиториал УРСС.

Корольова, А. В. (2008). Стратегії і тактики комунікативної поведінки учасників спілкування в ситуаціях конфлікту. Studia Linguistica. Збірник наукових праць 1, 48-53.

Костина, И. А. (2017). Семантическая аттракция семем глагольных наименований физического восприятия в русском и английском языках. Известия Волгоградского государственного педагогического университета. 6 (119), 120-123.

Маковский, М. М. (1971). Теория лексической аттракизии (опыт функииональной типологии лексико-семантических систем). Москва: Наука.

Пастернак, Т. А. (2011). Комунікативні стратегії і тактики дискурсу “співбесіда при прийомі на роботу”. Studia Linguistica: Збірник наукових пращь. 5 (2), 363-367.

Полтавець, Ю. С. (2013). Явище атракції: вияв на різних мовних рівнях. Лінгвістичні дослідження: 3б. наук. пращь ХНПУ ім. Г.С. Сковороди. 36, 210-217.

Славова, Л. Л. (2006) Комунікативні стратегії та тактики у сучасному масмедійному політичному дискурсі: зіставний аспект (на матеріалі українських та американських Інтернет-джерел). Вісник Житомирського державного університету імені Івана Франка. (27), 116-117.

Шейгал, Е. И. (2000). Семиотика политического дискурса. Москва, Волгоград: Перемена.

Bach, K. (1999). The myth of conventional implicature. Linguistics and philosophy. 22 (4), 367-421.

Bach, K. (2012). Saying, meaning, and implicating. The Cambridge handbook of pragmatics (pp. 23-45). New York: Cambridge University Press.

Brown, P. \& Levinson, S. C. (1987). Universals in language usage: Politeness phenomena. Questions and politeness: Strategies in social interaction (pp. 56-324). Cambridge: Cambridge UP.

Brown, P. \& Levinson, S. (1978). Politeness. Cambridge: Cambridge University Press.

Grice, H. P. (1975). Logic and conversation. Syntax and semantics 3: Speech acts (pp. 41-58). New York: Academic Press.

Grice, H. P. (1989). Studies in the way of words. Cambridge, MA: Harvard University Press.

Horn, L. R. (2007). Towards a Fregean pragmatics. Voraussetzung, Nebengedanke, Andeutung. Explorations in pragmatics: Linguistic, cognitive and intercultural aspects (pp. 39-69).

Jefferson, G. (1972). Side sequences. Studies in social interaction (pp. 294-338). New York: Free Press.

Karttunen, L. \& Peters, S. (1979). Conventional implicatures in Montague grammar. Syntax and Semantics. 11: Presupposition. 1-56.

Karttunen, L. \& Zaenen, A. (2005). Veridicity. Annotating, extracting and reasoning about time and events. Available at http://drops.dagstuhl.de/opus/2005/314 
Kravchenko, N. (2017a). Illocution of direct speech acts via conventional implicature and semantic presupposition. Lege artis. Language yesterday, today, tomorrow. II (1), 128-168.

Kravchenko, N. (2017b). Indirect speech acts' via conversational implicatures and pragmatic presuppositions. Cognition, communication, discourse. 14, 54-66.

Kravchenko, N., Pasternak, T. (2018). Multifacet Pragmatics of Russian Post-soviet Jokes. The languages of humor: Jokes Caricatures \& Slapstick. Bloomsbury Publishing Plc.

Kravchenko, N. \& Pasternak, T. (2016). Politeness strategies via speech acts and conversational implicatures. Science and Education a New Dimension. Philology. 14 (25), 105. 60-63.

Leech, G. N. (1983). Principles of Pragmatics. London: Longman.

Potts, C. (2005). The logic of conventional implicatures. Oxford studies in theoretical linguistics. Oxford: Oxford University Press.

Potts, C. (2013). Presupposition and implicature. Handbook of contemporary semantic theory. 2. Available at http://www.semanticsarcheve.net

Rieber, S. D. (1997). Conventional implicatures as tacit performatives. Linguistics and philosophy. 20 (1), 51-72.

Sacks, H. G. at al. (1992). Lectures on Conversation. 1, 2. Oxford: Wiley-Blackwell.

Schegloff, E. A. (2000). Overlapping talk and the organization of turn-taking for conversation. Language in Society. 29 (1), 63.

Sperber, D. \& Wilson, D. (1995). Relevance: Communication and cognition. Oxford: Cambridge MA.

\section{REFERENCES}

Voroniuk, O. V. (1998). Paronimichna atraktsiia v zaholovku tekstiv anhlomovnoi masovoi komunikatsii. (Avtoref. dys. kand. filol. nauk). Odesa.

Daschenko, N. L. (1996). Paronimichna atraktsiia v ukrains 'kij poezii 60-80-h rokiv XX st. : (Avtoref. dys. kand. filol. nauk). Kyiv.

Dmytruk, O. V. (2006). Manipuliatyvni stratehii v suchasnij anhlomovnij komunikatsii (na materiali drukovanykh ta internet-vydan' 2000-2005 rokiv). (Avtoref. dys. kand. filol. nauk). Kyiv.

Issers, O. S. (2002). Kommunikativnyie stratehii i taktiki russkoj rechi. Moskva: Editorial URSS.

Koroliova, A. V. (2008). Stratehii i taktyky komunikatyvnoi povedinky uchasnykiv spilkuvannia v sytuatsiiakh konfliktu. Studia Linguistica. Zbirnyk naukovykh prats. 1, 48-53.

Kostina, Y. A. (2017). Semanticheskaia attraktsiia semem hlahol'nykh naimenovanij fizicheskoho vospriiatiia v russkom i anhlijskom iazykakh. Izvestiia Volhohradskoho hosudarstvennoho pedahohicheskoho universiteta. 6 (119), 120-123.

Makovskij, M. M. (1971). Teoriia leksicheskoj attraktsii (opyt funktsional'noj tipolohii leksikosemanticheskih sistem). Moskva: Nauka.

Pasternak, T. A. (2011). Komunikatyvni stratehii i taktyky dyskursu "spivbesida pry pryiomi na robotu". Studia Linguistica: Zbirnyk naukovykh prats. 5 (2), 363-367.

Poltavets', Yu. S. (2013). Yavyshche atraktsii: vyiav na riznykh movnyh rivniah. Linhvistychni doslidzhennia: Zb. nauk. prats KNPU im. H.S. Skovorody. 36, 210-217.

Slavova, L. L. (2006) Komunikatyvni stratehii ta taktyky u suchasnomu masmedijnomu politychnomu dyskursi: zistavnyj aspekt (na materiali ukrains'kykh ta amerykans'kykh Internet-dzherel). Visnyk Zhytomyrs'koho derzhavnoho universytetu imeni Ivana Franka. (27), 116-117.

Sheihal, E. Y. (2000). Semiotika politicheskoho diskursa. Moskva, Volhohrad: Peremena.

Bach, K. (1999). The myth of conventional implicature. Linguistics and philosophy. 22 (4), 367-421.

Bach, K. (2012). Saying, meaning, and implicating. The Cambridge handbook of pragmatics (pp. 23-45). New York: Cambridge University Press.

Brown, P. \& Levinson, S. C. (1987). Universals in language usage: Politeness phenomena. Questions and politeness: Strategies in social interaction (pp. 56-324). Cambridge: Cambridge UP. 
Brown, P. \& Levinson, S. (1978). Politeness. Cambridge: Cambridge University Press.

Grice, H. P. (1975). Logic and conversation. Syntax and semantics 3: Speech acts (pp. 41-58). New York: Academic Press.

Grice, H. P. (1989). Studies in the way of words. Cambridge, MA: Harvard University Press.

Horn, L. R. (2007). Towards a Fregean pragmatics. Voraussetzung, Nebengedanke, Andeutung. Explorations in pragmatics: Linguistic, cognitive and intercultural aspects (pp. 39-69).

Jefferson, G. (1972). Side sequences. Studies in social interaction (pp. 294-338). New York: Free Press.

Karttunen, L. \& Peters, S. (1979). Conventional implicatures in Montague grammar. Syntax and Semantics. 11: Presupposition. 1-56.

Karttunen, L. \& Zaenen, A. (2005). Veridicity. Annotating, extracting and reasoning about time and events. Available at http://drops.dagstuhl.de/opus/2005/314

Kravchenko, N. (2017a). Illocution of direct speech acts via conventional implicature and semantic presupposition. Lege artis. Language yesterday, today, tomorrow. II (1), 128-168.

Kravchenko, N. (2017b). Indirect speech acts' via conversational implicatures and pragmatic presuppositions. Cognition, communication, discourse. 14, 54-66.

Kravchenko, N., Pasternak, T. (2018). Multifacet Pragmatics of Russian Post-soviet Jokes. The languages of humor: Jokes Caricatures \& Slapstick. Bloomsbury Publishing Plc.

Kravchenko, N. \& Pasternak, T. (2016). Politeness strategies via speech acts and conversational implicatures. Science and Education a New Dimension. Philology. 14 (25), 105. 60-63.

Leech, G. N. (1983). Principles of Pragmatics. London: Longman.

Potts, C. (2005). The logic of conventional implicatures. Oxford studies in theoretical linguistics. Oxford: Oxford University Press.

Potts, C. (2013). Presupposition and implicature. Handbook of contemporary semantic theory. 2. Available at http://www.semanticsarcheve.net

Rieber, S. D. (1997). Conventional implicatures as tacit performatives. Linguistics and philosophy. $20(1), 51-72$.

Sacks, H. G. at al. (1992). Lectures on Conversation. 1, 2. Oxford: Wiley-Blackwell.

Schegloff, E. A. (2000). Overlapping talk and the organization of turn-taking for conversation. Language in Society. 29 (1), 63.

Sperber, D. \& Wilson, D. (1995). Relevance: Communication and cognition. Oxford: Cambridge MA.

Дата надходження до редакиії 08.02.2018 p.

Ухвалено до друку 27.04.2018 p. 